WellBeing International

WBI Studies Repository

$1-2009$

\title{
Landscape Heterogeneity and Marine Subsidy Generate Extensive Intrapopulation Niche Diversity in a Large Terrestrial Vertebrate
}

Chris T. Darimont

University of Victoria

Paul C. Paquet

University of Calgary

Thomas E. Reimchen

University of Victoria

Follow this and additional works at: https://www.wellbeingintlstudiesrepository.org/popdhab

Part of the Animal Studies Commons, Environmental Studies Commons, and the Population Biology

Commons

\section{Recommended Citation}

Darimont, C. T., Paquet, P. C., \& Reimchen, T. E. (2009). Landscape heterogeneity and marine subsidy generate extensive intrapopulation niche diversity in a large terrestrial vertebrate. Journal of Animal Ecology, 78(1), 126-133.

This material is brought to you for free and open access by WellBeing International. It has been accepted for inclusion by an authorized administrator of the WBI Studies Repository. For more information, please contact wbisr-info@wellbeingintl.org.

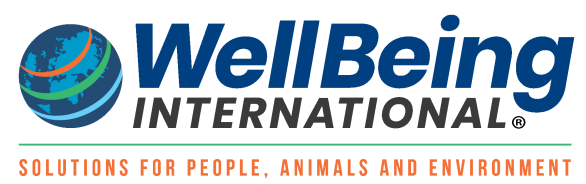




\title{
Landscape heterogeneity and marine subsidy generate extensive intrapopulation niche diversity in a large terrestrial vertebrate
}

\author{
Chris T. Darimont ${ }^{1,2 *}$, Paul C. Paquet ${ }^{2,3}$ and Thomas E. Reimchen ${ }^{1}$ \\ ${ }^{1}$ Department of Biology, PO Box 3020, Station CSC, University of Victoria, Victoria, BC, Canada V8W 3N5; ${ }^{2}$ Raincoast \\ Conservation Foundation, PO Box 86, Denny Island, BC, Canada VOT 1B0; and ${ }^{3}$ Faculty of Environmental Design, \\ University of Calgary, 2500 University Drive NW, Calgary, AB, Canada T2N 1N4
}

\begin{abstract}
Summary
1. Inquiries into niche variation within populations typically focus on proximate ecological causes such as competition. Here we examine how landscape heterogeneity and allochthonous (marine) subsidy might ultimately generate intrapopulation niche diversity.

2. Using stable isotope analysis, we detected extensive terrestrial-marine isotopic niche variation among subpopulations, social groups, and individual grey wolves (Canis lupus) that occupy a spatially heterogeneous landscape in coastal British Columbia comprising a mainland area and adjacent archipelago.

3. The inner island subpopulation exhibited the widest isotopic niche in the population, consuming extensive terrestrial and marine resources. Mainland and outer island subpopulations occupied comparatively narrow and primarily terrestrial, and primarily marine, niches respectively. Within these biogeographical subpopulations, social groups also diverged in niche.

4. To support examination at the individual level, we used an isotopic approach to test Van Valen's (1965) niche variation hypothesis. Consistent with the hypothesis, we observed that among-individual variation increased with subpopulation niche width.

5. Patterns at all levels related to how a spatially heterogeneous coastal landscape structured the competitive environment, which in turn mediated the availability and use of terrestrial and marine resources. Broadly, our results suggest that spatial heterogeneity and allochthonous subsidy - both widespread but commonly subject to contemporary anthropogenic change - might provide novel opportunities for examination and conservation of ecological variation within populations.
\end{abstract}

Key-words: allochthony, dietary variation, grey wolf, individual niche, spatial heterogeneity

\section{Introduction}

Although the niche concept was conceived and remains commonly applied at the species level (e.g. Hutchinson 1957; Owen-Smith \& Mills 2008), it can also be applied to individuals and scaled up subsequently to higher levels of organization. Such perspective was first articulated in Van Valen's (1965) niche variation hypothesis. Examining the niches of mainland and island birds, Van Valen proposed that population niche expansion on islands, where interspecific competition was reduced, can occur via increased among-individual variation

*Correspondence author. Environmental Studies Department, University of California, Santa Cruz, 405 Interdisciplinary Sciences Building, 1156 High Street, Santa Cruz, CA 95064, USA. E-mail: darimont@ucsc.edu in resource use. Evidence has since accumulated across taxa showing that individuals can vary markedly in niche, and in many cases, among-individual variation can comprise most of a population's total niche width (reviews in Bolnick et al. 2003, 2007).

Although inter- and intraspecific competition are commonly invoked as causes for intrapopulation niche variation (and associated phenotypic characters; e.g. Roughgarden 1972; Bolnick 2001; Bolnick et al. 2003; Svanbäck \& Persson 2004; Svanbäck \& Bolnick 2007), the potential influence of higher-level ecological context remains underdeveloped. Here we examine if landscape heterogeneity (defined here as coarse-scale spatial variation) and allochthonous food subsidy can ultimately generate niche variation within populations. Across a naturally heterogeneous landscape comprising a mainland and network of oceanic islands, we investigate how the foraging niche of a 
large terrestrial carnivore varies among subpopulations, social groups, and individuals.

Large-scale spatial heterogeneity in this mainland and archipelago area might create conditions for increased intraspecific competition. In island-like systems, relationships between predator and prey often depart from those observed in more homogeneous landscapes and are often characterized by depletion of prey (Kareiva, Mullen \& Southwood 1990; Dolman $\&$ Sutherland 1997). Under conditions of resource scarcity, consumers should minimize intraspecific competition by supplementing their diets with additional items (Roughgarden 1972; Stephens \& Krebs 1986).

In a coastal area, such supplementary items might include allochthonous subsidies from the ocean. Such flow of material across habitat boundaries is known to have significant effects on the behaviour and life history in many taxa (reviews in Polis \& Hurd 1996; Jefferies 2000). Marine resources - and particularly spawning salmon (Oncorhynchus spp.), which offer a predictable, nutritiously valuable, and spatially and temporally constrained resource - attract many terrestrial consumers (review in Schindler et al. 2003).

These resource qualities should promote competition. In coastal British Columbia, wolves (Canis lupus, Linnaeus), black bears (Ursus americanus, Pallas), and brown bears (Ursus arctos, Linnaeus) are the primary terrestrial predators of salmon and other marine foods. Landscape heterogeneity, however, structures their distribution. Wolves occur everywhere, black bears are rare or absent on outer islands but common on the mainland and inner islands, and brown bears are absent from most islands (Nagorsen 1990; Paquet et al. 2006). Thus, wolves might experience increasingly relaxed interspecific competition for marine resources on islands and with greater isolation.

The coupling of increased intra- and relaxed interspecific competition encountered by island wolves might promote increased niche width on islands, but such a process could be achieved through two means: (i) all island individuals might use the full suite of available terrestrial and marine resources, or (ii) consistent with the niche variation hypothesis, individuals might maintain limited resource bases but diverge in niche space from others, thus increasing population niche width via greater among-individual variation (Van Valen 1965; Bolnick et al. 2003, 2007). Our previous, and preliminary, examination (using faecal data) indicated that island wolves departed from a primarily terrestrial 'mainland' niche, comprised predominantly of deer (Odocoileus hemionus, Rafinesque), and did so increasingly with greater island isolation. Marine items, especially spawning salmon and smaller marine-oriented mammals, replaced deer, thus expanding population-level niche width into an increasingly marine domain (Darimont et al. 2004). This previous examination using faecal data, however, was limited in temporal resolution and, critically, could not differentiate resource use among individuals.

How might persistent niche variation at the individual level be assessed? Stable isotope analysis of tissue provides a dietary niche proxy that tracks the flow of atoms (carbon and nitrogen, here) from resources to consumers (reviews in Layman et al. 2007a; Newsome et al. 2007). Data offer foraging information about individuals that share otherwise common ecological conditions over long periods, permitting investigations of intrapopulation variation (Bearhop et al. 2004). Relevant here, marine foods contain elevated carbon and nitrogen isotope signatures compared with terrestrial foods (Schoeninger \& Deniro 1984), providing opportunity to account for niche variation along a terrestrial-marine dimension.

Using isotopic data, we test three interrelated hypotheses. First, at the population level, landscape heterogeneity should influence niche variation. Specifically, island wolves, which encounter conditions of increased intra- and reduced interspecific competition, should show greater niche width relative to mainland conspecifics. Second, at the subpopulation level, island wolves should attain this increase in niche width by incorporating marine subsidies. Third, at the individual level and following Van Valen's (1965) niche variation hypothesis, subpopulations with greater niche width (islands) should show greater variation among individuals.

\section{Materials and methods}

\section{STUDY AREA}

Brtish Columbia's central and north coasts, roughly $40000 \mathrm{~km}^{2}$, are remote areas sparsely disturbed by industrial activity. See Darimont et al. $(2004,2007)$ for detailed descriptions of the area. The 11 islands we sampled ranged from roughly 50 to $2300 \mathrm{~km}^{2}$, with distances to mainland (shortest island-hopping swimming distances) $100 \mathrm{~m}$ to $13 \mathrm{~km}$.

\section{SAMPLE COLLECTION AND ISOTOPIC ANALYSIS}

From 2001 to 2004, we sampled shed wolf hair from wolf reproductive sites and other areas of high use (Paquet et al. 2006; McAllister \& Darimont 2007). Wolves have one annual moult starting in late spring when the old coat sheds and a new one grows until late fall. Each isotopic sample from hair thus represents a record of individual niche for roughly half the previous year. We assume each sample originated from one wolf, as they were exclusively collected from resting beds and on most occasions, we sampled hair directly after viewing wolves. We sampled 17 groups (11 on islands, 6 from mainland). Samples per group ranged from 2 to 11 in each year, averaging $3 \cdot 4$. Isotopic sample preparation of hair from wolves and their prey, as well as salmon tissue, followed Darimont, Paquet \& Reimchen (2008). Isotopic signatures are expressed in delta notation $(\delta)$ in $\%$ units.

\section{STATISTICAL ANALYSES}

We used a general linear mixed model to assess how variation in $\delta^{13} \mathrm{C}$ and $\delta^{15} \mathrm{~N}$ in wolves was structured among biogeographical regions, social groups nested within regions, individuals nested within groups, and years (Table 1). We defined inner islands as those directly adjacent to the mainland. We also used ANOvas to examine deer signatures among regions to examine if potential differences in wolves simply might be tracking changes in deer (or plants) among regions. Finally, because we lack detailed data on how competition 
Table 1. Results of a general linear mixed model to account for variation in $\delta^{13} \mathrm{C}$ and $\delta^{15} \mathrm{~N}$ among wolves (Canis lupus, $n=78$ ) of coastal British Columbia, 2000 to 2003. Shown are results from type III tests of fixed effects, and estimates of covariance parameters. Wald's $Z$ statistic (and corresponding $P$ ) assesses whether random effects significantly structure variance

\begin{tabular}{|c|c|c|c|c|c|c|c|}
\hline Dependent/effect & Variable & d.f. & $F$ & $\begin{array}{l}\text { Estimate of } \\
\text { covariance }\end{array}$ & SE & Wald's $Z$ & $P$ \\
\hline \multicolumn{8}{|l|}{$\delta^{13} \mathrm{C}$} \\
\hline & Intercept & $1,11 \cdot 39$ & $1723 \cdot 61$ & & & & $0 \cdot 001$ \\
\hline Fixed & Region & $2,13 \cdot 72$ & $11 \cdot 49$ & & & & $0 \cdot 001$ \\
\hline Random & Group (region) & & & $1 \cdot 80$ & $0 \cdot 92$ & 1.96 & $0 \cdot 050$ \\
\hline Random & Individual (group) & & & $1 \cdot 39$ & $0 \cdot 31$ & $4 \cdot 52$ & $0 \cdot 001$ \\
\hline Random & Year & & & $0 \cdot 20$ & $0 \cdot 24$ & $0 \cdot 86$ & $0 \cdot 392$ \\
\hline Random & Error & & & $0 \cdot 08$ & $0 \cdot 08$ & $1 \cdot 06$ & $0 \cdot 291$ \\
\hline \multicolumn{8}{|l|}{$\delta^{15} \mathrm{~N}$} \\
\hline & Intercept & $1,10 \cdot 64$ & $369 \cdot 72$ & & & & $0 \cdot 001$ \\
\hline Fixed & Region & $2,13 \cdot 33$ & $12 \cdot 36$ & & & & 0.001 \\
\hline Random & Group (region) & & & $2 \cdot 20$ & $1 \cdot 03$ & $2 \cdot 12$ & 0.034 \\
\hline Random & Individual (group) & & & $0 \cdot 81$ & $0 \cdot 37$ & $2 \cdot 18$ & 0.029 \\
\hline Random & Year & & & $0 \cdot 43$ & $0 \cdot 43$ & $1 \cdot 00$ & $0 \cdot 317$ \\
\hline Random & Error & & & $0 \cdot 40$ & $0 \cdot 30$ & $1 \cdot 45$ & $0 \cdot 146$ \\
\hline
\end{tabular}

varies among regions, we examined how the following island characteristics might influence marine resource use by island wolves (indexed by average pack $\delta^{13} \mathrm{C}$ signatures across years): (i) island size, and (ii) isolation, given that these can influence predator-prey dynamics, and (iii) island shape - indexed in a geographical information system as $\left(0 \cdot 25 \times\right.$ perimeter) $\mathrm{sqrt}^{-1} /$ (area) (Paquet et al. 2006). We reasoned that island shapes with greater perimeter to area ratios (i.e. shoreline) would offer wolves more 'marine mammal' resources (see below). This allowed us to evaluate whether island wolves might use more marine resources because more are available. We used Akaike information criterion (AIC) $)_{c}$ to evaluate models comprising all combinations of these parameters plus a size-isolation interaction term and identified models with $\Delta \mathrm{AIC}_{c}<4$ (Burnham \& Anderson 1998).

To examine how common prey might contribute to intrapopulation niche diversity within wolves, we used ISOERROR. This isotopic mixing model estimates the assimilation of carbon and nitrogen from pre-defined food groups into consumer tissue, incorporating isotopic variation in both consumers and prey. Specifically, ISOERROR uses mean, sample sizes, standard deviation, and correlations (between signatures within each prey group) of three prey groups and the consumer (Phillips \& Gregg 2001). To characterize important prey, we sampled the three most frequent foods identified in wolf faeces: deer, salmon (Oncorhynchus spp.), and an aggregate 'marine mammal' group, which included harbour seals, river otters, and mink (Phoca vitulina, Gray; Lontra canadensis, Schreber; Mustela vison, Schreber). We aggregated these three species because they are the most common prey after deer and salmon, have similar marine-based diets, co-exist in shoreline/near-shore habitats, and show similar isotopic signatures (Fig. 3). Collectively, deer, salmon and these marine mammals occurred in $83 \%$ of 2466 wolf faeces collected during summer and fall (period of wolf hair growth) across roughly the same area and years. Although additional prey were detected in these faeces, they were scattered across at least 11 other species (summarized from Darimont et al. 2004, 2008; Bryan et al. 2006). Nonetheless, to assess their potential influence on wolf diet, we project isotopic values of species for which we have data (Fig. 3). Finally, we note here that $\delta^{13} \mathrm{C}$ and $\delta^{15} \mathrm{~N}$ in deer did not vary across biogeographical regions (Fig. 2). Likewise, salmon collected from one mainland and one island site did not vary ( $t$-tests, both
$P>0.520)$. Similarly, marine mammals collected from the mainland, inner, and outer islands did not vary, individually or in aggregation (ANOvAs, all $P>0 \cdot 114$ ).

We used the following protocol for estimating prey signatures. Deer $(n=66)$ and marine mammal $(n=19)$ hair was sampled from wolf faeces. We assumed no difference in signatures between prey hair and prey tissue that wolves consumed (i.e. muscle, viscera). Salmon samples were derived from 16 recently senesced Oncorhynchus gorbuscha (Walbaum) and Oncorhynchus keta (Walbaum), species that constitute most of the area's spawning biomass. We used 'prey tissue'to-'wolf hair' fractionation values of $+2 \cdot 6$ and $+3 \cdot 4 \%$ for carbon and nitrogen respectively (Roth \& Hobson 2000). In Results, we focus on the range of contributions from each prey group, not mean estimates (Phillips \& Gregg 2001).

We also present here a method to examine the niche variation hypothesis using isotopic data and under a similar conceptual framework as Bolnick et al. (2007). Specifically, for each biogeographical region, we modified two metrics described by Layman et al. (2007a). First, we calculated total area (TA), defined by the minimum convex polygon bounding the most divergent individuals (Fig. 1b). We suggest this aggregate measure to describe the isotopic range of resources used by a (sub)population can provide a proxy for 'population niche width'. Although differing from Roughgarden's (1972) classical description of population niche width employed in Bolnick et al. (2007), it is similar in character; in foodwebs where isotopic values of common foods are known and distinct (as here; Fig. 3), larger values would indicate a greater range of foods used by a (sub)population. Second, for each region, we also calculated mean nearest neighbour distance (NND), defined by the average Euclidean distance among each individual to its nearest neighbour. Thus, mean NND offers an estimate of dietary variation among individuals similar to the 'proportional similarity index' (Schoener 1968) used by Bolnick et al. (2007). Accordingly, TA and mean NND can provide isotopic proxies for what Bolnick et al. $(2003,2007)$ referred to as 'population niche width' and 'degree of diet variation'.

Comparisons of TA and mean NND among subpopulations of unequal sample sizes are problematic. Consequently, we wrote routines in MATLAB (The Mathworks, Inc., Natick, MA, USA) to compute the distribution of these metrics following iterative (10 000 times) resampling, without replacement, of the larger subpopulation(s) for 

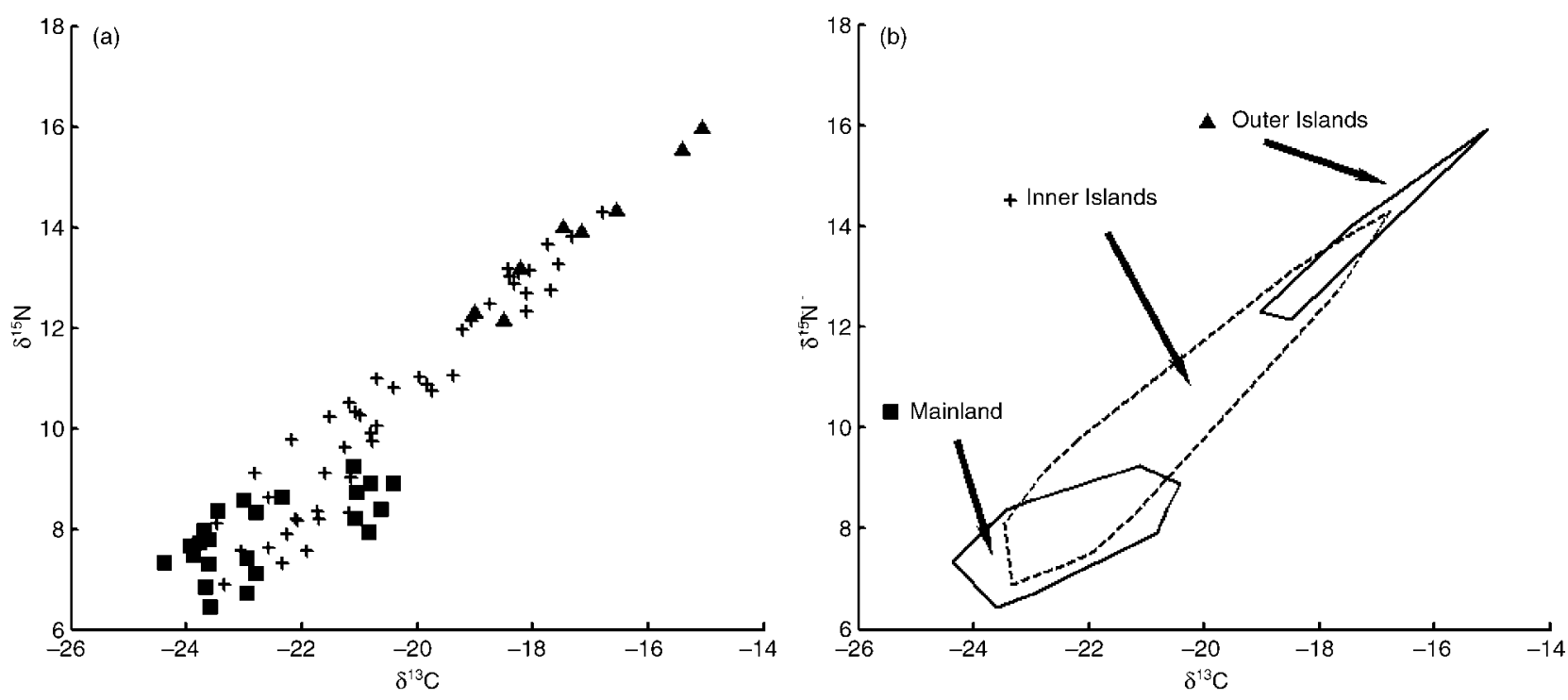

Fig. 1. $\delta^{13} \mathrm{C}$ and $\delta^{15} \mathrm{~N}$ in wolves (Canis lupus) of coastal British Columbia, 2000 to 2003. (a) individual wolves, $n=78$. (b) raw isotopic niche widths of mainland, inner, and outer island subpopulations ( $n=24,46,8$ respectively), defined by total area, the minimum convex polygon bounding most divergent individuals.

the same number of samples in the least represented subpopulation. These distributions were then compared to observed values in the least represented subpopulation.

\section{Results}

Isotopic signatures in wolves were variable across the study area. Reflecting marine influence, $\delta^{13} \mathrm{C}$ and $\delta^{15} \mathrm{~N}$ signatures in wolf hair ranged widely $(9 \cdot 3 \%$ and $9 \cdot 5 \%$, respectively) and were correlated $(r=0.976, n=78, P<0.001$, Fig. 1a). Total isotopic variation was significantly structured by biogeographical region, social groups nested within region, and individuals nested within groups (Table 1). Using island data only to examine what island characters might influence marine resource use by wolves, the lone model in the top set defined by $\Delta \mathrm{AIC}_{c}<4$ included only island isolation (and intercept). This model shows that mean $\delta^{13} \mathrm{C}$ of island groups increased with island isolation $(r=0 \cdot 760, n=11$ islands, $P=0 \cdot 007)$.

Wolves from the mainland, inner, and outer islands had significantly different isotopic signatures, with mainland wolves showing the lowest and outer island wolves showing the highest values (region as fixed effect in Table 1; Figs 1 and 2 ). In contrast, deer signatures, representative of terrestrial foodwebs, did not vary among regions $\left(\delta^{13} \mathrm{C}\right.$ ANOVA, $F_{2,71}=0 \cdot 66, n=70, P=0 \cdot 518 ; \delta^{15} \mathrm{~N}$ ANOVA, $F_{2,71}=0 \cdot 16, n=70$, $P=0 \cdot 849$; Fig. 2).

ISOERROR estimates showed that island subpopulations diverged from a diet dominated by deer on the mainland to one increasingly dominated by salmon and marine mammals with greater island isolation (Table 2, Fig. 3). Ranges of estimated ingestion of deer by island wolves were lower (and non-overlapping) with ranges estimated for mainland conspecifics. Although ranges for marine mammal and salmon ingestion were broad in all regions, upper values on islands were roughly 1.5 to 3 times that of mainland estimates (Table 2). How additional prey would influence signatures in wolves can be visualized in Fig. 3 .

Wolves of all islands exhibited a wider isotopic niche (TA) compared with mainland conspecifics (Fig. 4a). Island wolves also showed higher among-individual variation, as measured by mean NND (Fig. 4b). Separating inner from outer islands revealed additional differences. Repeating the above process, comparisons between mainland and inner islands showed even greater differences (data not shown). We then iteratively re-sampled only eight wolves from mainland and inner subpopulations to compare with observed measures in outer island wolves (where $n=8$ ). Niche width (TA) on outer islands was the lowest among regions (Fig. 4c). Mean NND, a measure of among-individual variation, was intermediate, occurring within $95 \%$ confidence intervals of re-sampled mainland and inner island populations (Fig. 4d).

\section{Discussion}

Spatial heterogeneity can ultimately drive ecological processes, including variation within food webs of populations (Polis \& Hurd 1996; Polis, Anderson \& Holt 1997). Hutchinson (1957) recognized this, invoking the 'mosaic nature of the environment' in his niche concept. Also examining isotopic niche variation across heterogeneous space, Layman et al. (2007b) demonstrated a collapse in trophic niche width of fish populations following human-caused fragmentation of estuaries. We show here, in a large terrestrial vertebrate, how a naturally heterogeneous coastal landscape that offers marine resources can ultimately generate intrapopulation diversity in isotopic niche at the subpopulation, social group, and individual levels. Although we lack data on resource abundance competition 

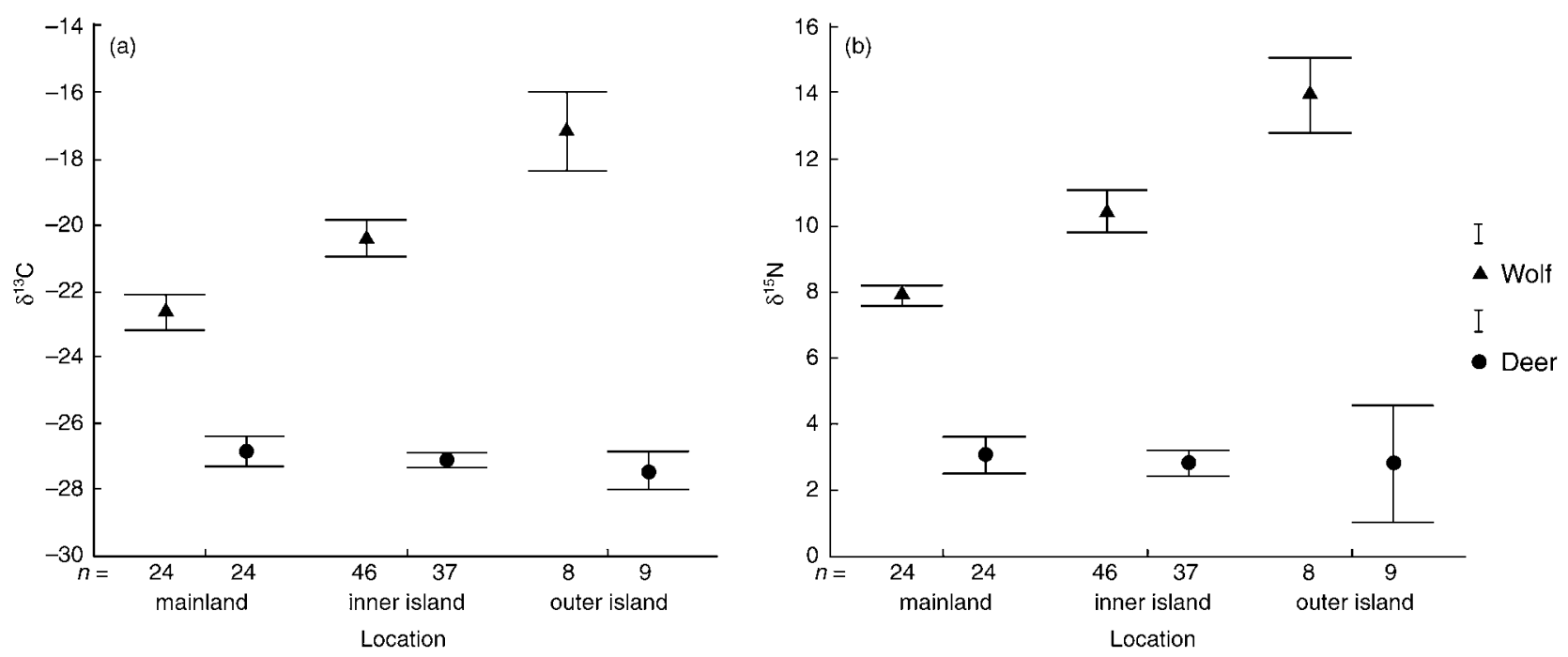

Fig. 2. $\delta^{13} \mathrm{C}$ and $\delta^{15} \mathrm{~N}$ variation in wolves (Canis lupus, $n=78$ ) and deer (Odocoileus hemionus, $n=70$ ) among mainland, inner, and outer island regions, coastal British Columbia, 2000-03.

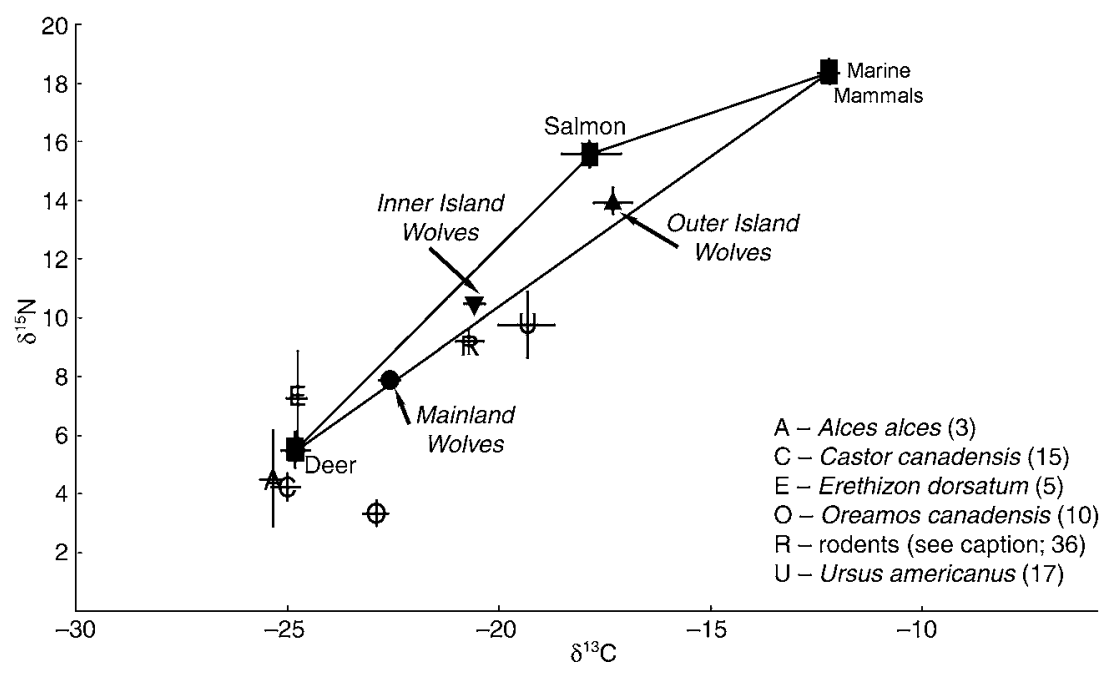

Fig. 3. ISOERROR 'mixing triangle'. Mean and $\mathrm{SE} \delta^{13} \mathrm{C}$ and $\delta^{15} \mathrm{~N}$ in wolves (Canis lupus) of the mainland, inner, and outer islands, and in their most common prey (corrected for fractionation). Additional prey available to wolves (and sample size) also shown. Rodents are Sorex monticolus, Peromyscus maniculatus, and Clethrionomys spp.

Table 2. ISOERROR estimates of assimilated biomass (percentage) from three prey groups (deer, salmon, and marine mammals) to the diet of wolves (Canis lupus) occupying the mainland, inner, and outer islands of coastal British Columbia, 2000 to 2003. Shown are mean, (SE), and $[95 \% \mathrm{CI}]$

\begin{tabular}{lllr}
\hline Location & Deer & Prey marine mammals & Salmon \\
\hline Mainland $(n=24)$ & $\mathbf{8 2 \cdot 2}(4 \cdot 7)[72 \cdot 9-91 \cdot 5]$ & $\mathbf{1 9 \cdot 5}(9 \cdot 9)[0-34 \cdot 4]$ & $\mathbf{- 1 \cdot 7}(14 \cdot 5)[-8 \cdot 6$ to $27 \cdot 1]$ \\
Inner Islands $(n=46)$ & $\mathbf{6 0} \cdot \mathbf{1}(7 \cdot 4)[45 \cdot 3-74 \cdot 8]$ & $\mathbf{3 0 \cdot 6}(14 \cdot 1)[2 \cdot 9-51 \cdot 6]$ & $\mathbf{9 \cdot 2}(21 \cdot 5)[0-51 \cdot 6]$ \\
Outer Islands $(n=8)$ & $\mathbf{3 1} \cdot 9(12 \cdot 3)[7 \cdot 0-56 \cdot 8]$ & $\mathbf{5 1} \cdot 7(24 \cdot 2)[3 \cdot 1-100]$ & $\mathbf{1 6 \cdot 4}(36 \cdot 5)[0-89 \cdot 4]$ \\
All Islands $(n=54)$ & $\mathbf{5 6 \cdot 0}(7 \cdot 8)[40 \cdot 6-71 \cdot 4]$ & $\mathbf{3 3} \cdot \mathbf{9}(14 \cdot 9)[4 \cdot 6-63 \cdot 2]$ & $\mathbf{1 0 \cdot 1}(22 \cdot 7)[0-54 \cdot 6]$ \\
\hline
\end{tabular}

among areas, below we offer working hypotheses to explain why these terrestrial carnivores adopt a more marine and individualistic niche on islands.

Isotopic data provide an integrative estimate of realized niche and might differ from those inferred from phenotypic (i.e. trophic) characters or direct examinations of food use (e.g. gut/scat contents). Here, our foodweb reconstruction (Fig. 3) and an isotopic mixing model show how differential consumption of common prey could generate persistent niche variation among regions, social groups, and individuals. Moreover, although our focus is on marine-terrestrial niche variation, we acknowledge that individuals who diverged in resource use among only terrestrial prey might show less isotopic variation than individuals that consumed either deer or salmon, which differ widely in signatures. Thus, the total area measure might underestimate niche width of subpopulations 

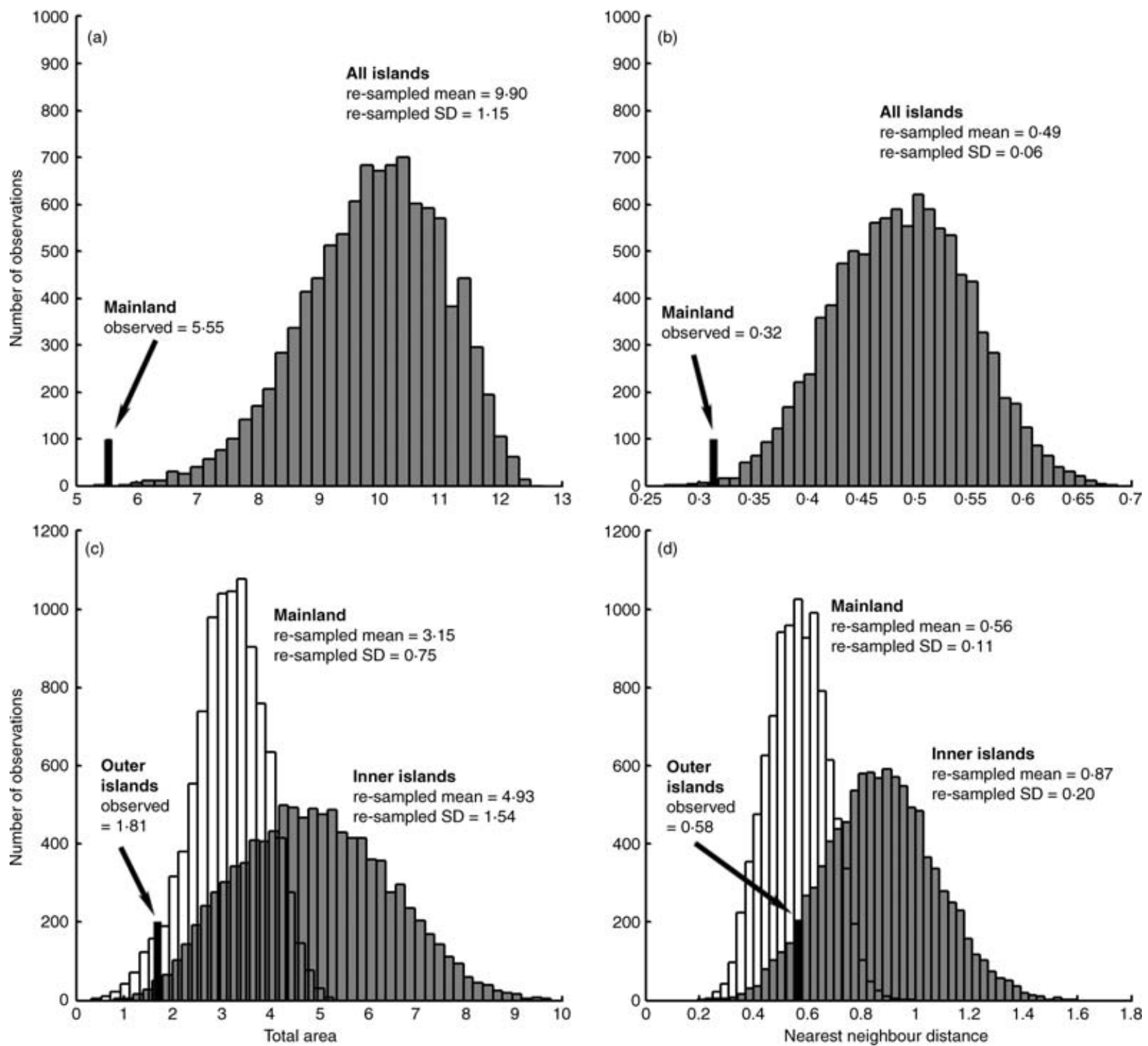

Fig 4. Comparisons of total area (TA) and mean nearest neighbour distance (NND) between mainland $(n=24)$ and all islands $(n=54 ; \mathrm{a}, \mathrm{b})$, and among mainland, inner $(n=46)$, and outer island wolves $(n=8 ; \mathrm{c}, \mathrm{d})$. To account for different sample sizes, larger subpopulations were re-sampled 10000 times, and distributions compared to the observed datum for the least represented subpopulations, projected here as a dark vertical bar of arbitrary height.

compared with other dietary data. Finally, we note that isotopic variation among consumers can be not only a function of foraging but also factors that potentially affect nutrient assimilation (e.g. differential digestibility, body condition, growth rates, and physiological routing of nutrients; Layman et al. 2007a and references within). Despite these qualifications inherent to isotopic approaches, we suggest that (i) the trophic patterns we identify are likely much more substantial than any of these potential other effects (especially for inter-region comparisons), and (ii) for all our questions, such effects are unlikely to introduce ant systematic bias.

Subpopulations inhabiting mainland, inner, and outer islands occupied ecologically divergent niches. But why? We suggest that island wolves depart from a terrestrial niche due to reduced deer abundance coupled with greater access to marine resources. We discount a hypothesis of lower carrying capacity for deer on British Columbia islands. In fact, carnivorefree islands there support 'overabundant' deer populations (e.g. Stockton et al. 2005). Likewise, island shape (i.e. amount of shoreline) - our proxy for marine resource availability - also failed to explain variation in marine resource use among island wolves. Instead, we hypothesize that deer productivity and/ or immigration from other landmasses cannot offset predation (Kareiva et al. 1990; Dolman \& Sutherland 1997). This inferred dynamic seems sensitive to variation in isolation; we observed further departures from a terrestrial niche with greater island isolation. Our hypothesis is particularly plausible in a system with allochthonous resource supply, where densities (and ecological influence) of consumers can be greater than predicted by in situ productivity (Polis \& Hurd 1996; Roth 
2003). If our hypothesis is correct, by limiting deer and creating a more intense intraspecific competitive environment, marine-subsidized wolves on islands modify their own niche space.

Ecological opportunity for island wolves to broaden their niche into marine domains is likely afforded by a relaxed interspecific competitive environment. Larger-bodied mammalian carnivores are often able to exclude or restrict access of smaller carnivores to habitat or prey (Palomares \& Caro 1999). In our study area, presumably intense competition, especially with grizzly bears for salmon, would decline on islands and with greater isolation. This is consistent with estimates of salmon use by wolves being low to absent on the competitively rich mainland, but increasing to significant proportions on islands.

Similarly, differing ecological environments as influenced by landscape heterogeneity would also support niche diversity at finer levels. Although variation among social groups is driven by divergent ecological conditions among territories (Darimont et al. 2008), we focus here on interindividual variation. Individual wolves collectively occupied the widest isotopic niche on inner islands, where they face presumably increased intraspecific competition for deer. Under such resource scarcity, individuals are known to exploit underutilized resources (e.g. Svanbäck \& Bolnick 2007; Tinker, Bentall $\&$ Estes 2008). Additionally, given reduced bear densities on inner islands, salmon and other marine foods become more available to exploit in comparatively empty 'marine niches'. Many cases of intrapopulation variation, including individual specializations, occur in similarly vacant niches (e.g. Werner \& Sherry 1987; Robinson \& Wilson 1994). In contrast, mainland wolves exhibited a narrow and primarily terrestrial niche, likely due to relatively abundant deer and/or reduced access to salmon. On outer islands, although released from competition with bears, wolves occupied an even narrower and primarily marine niche. We suggest this results from increased isolation greatly reducing deer densities and terrestrial prey species richness (Darimont et al. 2004).

How, ecologically, would a comparatively large niche width be expressed on inner islands? Not all individuals incorporated a similarly large suite of terrestrial and marine foods. Instead, individuals distributed themselves distantly from one another in isotopic niche space. Items like marine mammals, salmon, and likely other marine foods, being smaller than deer, would allow even solitary wolves to forage efficiently, minimizing failed capture attempts, risk of injury, and loss to scavengers. Also, additional prey species not included in the ISOERROR model might be commonly consumed by certain individuals and/or during certain times. Items more distant to the mixing triangle (Fig. 3) would have greater effect on signatures. For example, all other things being equal, consumption of mountain goats (Ovis canadensis, Shaw) on the mainland (the only region with goats) would deplete wolf $\delta^{15} \mathrm{~N}$ and might explain why mainland wolves had estimates of salmon consumption that overlapped zero.

What other processes underlie divergent foraging behaviour among individuals? In any biogeographical region, age, sex, morphology, experience, and heritable components to resource preference might be important (Bolnick et al. 2003). Cultural heritage, observed in wolves, might also contribute (Estes et al. 2003). Bolnick et al. (2007) additionally identified biomechanical, cognitive, or physiological tradeoffs that might prevent individuals from efficiently using diverse resources.

Regardless of underlying processes, our results showing increased among-individual niche variation under conditions of greater niche width conform to the niche variation hypothesis (Van Valen 1965; Bolnick et al. 2003, 2007). Although our comparison among three subpopulations does not constitute a thorough test, our approach might offer broad applicability. To our knowledge, no other study has addressed the hypothesis in a mammal system using a measure of realized niche or in any system with stable isotope analysis. Recently, Bolnick et al. (2007) found support for the hypothesis using - for the first time - data on realized niche (primarily gut contents) in fishes, lizards, frogs, and an intertidal gastropod. We agree with Bolnick et al. (2007); examining the niche variation hypothesis might be better served with data on realized niche. Any phenotypic trait, whether morphological or behavioural, might be selected for if it permits individuals to exploit under-used foods (e.g. Reimchen, Ingram \& Hansen 2008). Consequently, by providing a proxy for long-term realized niche, isotopic data, with the methods we present here plus careful interpretation (Bearhop et al. 2004, see also null models in Bolnick et al. 2007), provide fertile new ground in addressing the niche variation hypothesis.

If our results are representative of other systems, then several broad implications emerge. First, our results show that spatial heterogeneity can set in motion more proximate ecological causes (i.e. competition) that generate niche diversity within populations (see also Reimchen 1979; Darimont, Paquet \& Reimchen 2007). Second, although the influence of allochthonous subsidy on receiving populations is now well acknowledged (reviews in Polis \& Hurd 1996; Jefferies 2000), these resources likely are not exploited homogeneously within receiving populations. In fact, marine subsidy and particularly spawning salmon might be a significant agent of ecological diversification within terrestrial populations. Third, if predator control management - commonly applied to wolves - assumes all individuals are equally likely to kill a focal species, such efforts might in error target individuals or groups that deviate considerably, especially in populations with large potential niches (i.e. 'multi-prey systems'). In a conservation context, such a strikingly marine diet in this and any terrestrial consumer exposes potential threats such as overexploitation of fisheries and catastrophic oil spills. Finally, for any species and especially wildlife, management policy to safeguard an 'average population niche' might not adequately protect diversity within populations or the underlying processes.

\section{Acknowledgements}

We thank the Raincoast Conservation Foundation for primary funding. We also thank the National Geographic Society, Patagonia, WWF Canada, and the 
following Foundations for funding: Bullitt, McCaw, Summerlee, Vancouver, and Wilburforce. Earlier versions of the manuscript benefited from comments from D. Bolnick, M. Hocking, C. Layman, and T. Tinker. C. Wilmers assisted with MATLAB ${ }^{\circledR}$ and manuscript review. CTD was supported by NSERC Graduate and Postdoctoral Fellowships, and TER by NSERC operating grant A2354.

\section{References}

Bearhop, S., Adams, C.E., Waldron, S., Fuller, R.A. \& Macleod, H. (2004) Determining trophic niche width: a novel approach using stable isotope analysis. Journal of Animal Ecology, 73, 1007-1012.

Bolnick, D.I. (2001) Intraspecific competition favours niche width expansion in Drosophila melanogaster. Nature, 410, 463-466.

Bolnick, D.I., Svanbäck, R., Fordyce, J.A., Yang, L.H., Davis, J.M., Hulsey, C.D. \& Forister, M.L. (2003) The ecology of individuals: incidence and implications of individual specialization. American Naturalist, 161, 1-28.

Bolnick, D.I., Svanbäck, R., Araújo, M. \& Persson, L. (2007) More generalized populations are also more heterogeneous: comparative support for the niche variation hypothesis. Proceedings of the National Academy of Sciences, USA, 104, 10075-10079.

Bryan, H.M., Darimont, C.T., Reimchen, T.E. \& Paquet, P.C. (2006) Early ontogenetic diet in gray wolves, Canis lupus, of coastal British Columbia. Canadian Field-Naturalist, 120, 61-66.

Burnham, K.P. \& Anderson, D.R. (2002) Model selection and inference; a practical information-theoretic approach. Springer-Verlag New York, New York.

Darimont, C.T., Price, M.H.H., Winchester, N.N., Gordon-Walker, J. \& Paquet, P.C. (2004) Predators in natural fragments: foraging ecology of wolves in British Columbia's Central and North Coast archipelago. Journal of Biogeography, 31, 1867-1877.

Darimont, C.T., Paquet, P.C. \& Reimchen, T.E. (2007) Stable isotopic niche predicts fitness of prey in a wolf-deer system. Biological Journal of the Linnean Society, 90, 125-137.

Darimont, C.T., Paquet, P.C. \& Reimchen, T.E. (2008) Spawning salmon disrupt tight trophic coupling between wolves and ungulate prey in coastal British Columbia. BMC Ecology, 8, 14.

Dolman, P.M. \& Sutherland, W.J. (1997) Spatial patterns of depletion imposed by foraging vertebrates: theory, review and meta-analysis. Journal of Animal Ecology, 66, 481-494.

Estes, J.A., Riedman, M.L., Staedler, M.M., Tinker, M.T. \& Lyon, B.E. (2003) Individual variation in prey selection by sea otters: patterns, causes, and implications. Journal of Animal Ecology, 72, 144-155.

Hutchinson, R.E. (1957) Concluding remarks. Cold Spring Harbor Symposia on Quantitative Biology 22, 415-427.

Jefferies, R.L. (2000) Allochthonous inputs: integrating population changes and food-web dynamics. Trends in Ecology \& Evolution, 15, 19-22.

Kareiva, P., Mullen, A. \& Southwood, R. (1990) Population dynamics in spatially complex environments: theory and data. Philosophical Transactions of the Royal Society of London. Series B: Biological Sciences, 330, 175-190.

Layman, C.A., Arrington, D.A., Montaña, C.G. \& Post, D.M. (2007a) Can stable isotope ratios provide quantitative measures of trophic diversity within food webs? Ecology, 88, 42-48.

Layman, C.A., Quattrochi, J.P., Peyer, C.M. \& Allgeier, J.E. (2007b) Niche width collapse in a resilient top predator following ecosystem fragmentation. Ecology Letters, 10, 937-944.

McAllister, I. \& Darimont, C.T. (2007) The Last Wild Wolves. Ghosts of the Great Bear Rainforest. University of California Press, Berkeley, California.

Nagorsen, D.W. (1990) The mammals of British Columbia: a taxonomic catalogue. Royal British Columbia Museum Memoir, 4, 1-140.

Newsome, S.D., Martínez del Rio, C., Bearhop, S. \& Phillips, D.L. (2007) A niche for isotopic ecology. Frontiers in Ecology and the Environment, $\mathbf{5}$, 429-436.
Owen-Smith, N. \& Mills, M.G.L. (2008) Predator-prey size relationships in an African large-mammal food web. Journal of Animal Ecology, 77, 173183.

Palomares, F. \& Caro, T.M. (1999) Interspecific killing among mammalian carnivores. American Naturalist, 153, 492-508.

Paquet, P.C., Alexander, S.M., Swan, P.L. \& Darimont, C.T. (2006) The influence of natural landscape fragmentation and resource availability on connectivity and distribution of marine gray wolf (Canis lupus) populations on the Central Coast, British Columbia, Canada. Connectivity Conservation (eds K. Crooks \& M.A. Sanjayan), pp. 130-156. Cambridge University Press, Cambridge, UK.

Phillips, D.L. \& Gregg, J.W. (2001) Uncertainty in source partitioning using stable isotopes. Oecologia, 127, 171-179.

Polis, G.A. \& Hurd, S.D. (1996) Linking marine and terrestrial foodwebs: allochthonous input from the ocean supports high secondary productivity on small islands and coastal land communities. American Naturalist, 147 396-423.

Polis, G.A., Anderson, W.B. \& Holt, R.D. (1997) Towards an integration of landscape and food web ecology: the dynamics of spatially subsidized food webs. Annual Review of Ecology and Systematics, 28, 289-316.

Reimchen, T.E. (1979) Substrate heterogeneity, crypsis, and colour polymorphism in an intertidal snail (Littorina mariae). Canadian Journal of Zoology, 57, 1070-1085

Reimchen, T.E., Ingram, T. \& Hansen, S.C. (2008) Assessing niche differences of sex, armour and asymmetry phenotypes using stable isotope analyses in Haida Gwaii sticklebacks. Behaviour, 145, 561-577.

Robinson, B.W. \& Wilson, D.S. (1994) Character release and displacement in fishes: a neglected literature. American Naturalist, 144, 596-627.

Roth, J.D. (2003) Variability in marine resources affects arctic fox population dynamics. Journal of Animal Ecology, 72, 668-676.

Roth, J.D. \& Hobson, K.A. (2000) Stable-carbon and nitrogen isotopic fractionation between diet and tissue of captive red fox: implications for dietary reconstruction Canadian Journal of Zoology, 78, 848-852.

Roughgarden, J. (1972) Evolution of niche width. American Naturalist, 106, 683-718.

Schindler, D.E., Scheuerell, M.D., Moore, J.W., Gende, S.M., Francis, T.B. \& Palen, W.J. (2003) Pacific salmon and the ecology of coastal ecosystems Frontiers in Ecology and the Environment, 1, 1-37.

Schoener, T.W. (1968) The Anolis lizards of Bimini; resource partitioning in a complex fauna. Ecology, 49, 704-726.

Schoeninger, M.J. \& Deniro, M.J. (1984) Nitrogen and carbon isotopic composition of bone collagen from marine and terrestrial animals. Geochimica et Cosmochimica Acta, 48, 625-639.

Stephens, D.W. \& Krebs, J.R. (1986) Foraging Theory. Princeton University Press, Princeton, New Jersey.

Stockton, S.A., Allombert, S., Gaston, A.J. \& Martin, J.-L. (2005) A natural experiment on the effects of high deer densities on the native flora of coastal temperate rain forests. Biological Conservation, 126, 118-128.

Svanbäck, R. \& Bolnick, D.I. (2007) Intraspecific competition drives increased resource use diversity within a natural population. Proceedings of the Royal Society B: Biological Sciences, 274, 839-844.

Svanbäck, R. \& Persson, L. (2004) Individual specialization, niche width and population dynamics: implications for trophic polymorphisms. Journal of Animal Ecology, 73, 973-982.

Tinker, M.T., Bentall, G. \& Estes, J.A. (2008) Food limitation leads to behavioral diversification and dietary specialization in sea otters. Proceedings of the National Academy of Sciences, USA, 105, 560-565.

Van Valen, L. (1965) Morphological variation and width of the ecological niche. American Naturalist, 99, 377-390.

Werner, T.K. \& Sherry, T.W. (1987) Behavioral feeding specialization in Pinoroloxias inornata, the 'Darwin's Finch' of Cocos Island, Costa Rica. Proceedings of the National Academy of Sciences, USA, 84, 5506-5510.

Received 24 April 2008; accepted 11 August 2008

Handling Editor: Stuart Bearhop 